\title{
Birth position and obstetric anal sphincter injury: a population-based study of 113000 spontaneous births
}

\author{
Charlotte Elvander ${ }^{1}$, Mia Ahlberg ${ }^{1}$, Li Thies-Lagergren ${ }^{2 *}$, Sven Cnattingius ${ }^{1}$ and Olof Stephansson ${ }^{1}$
}

\begin{abstract}
Background: The association between birth position and obstetric anal sphincter injury (OASIS) in spontaneous vaginal deliveries is unclear.

Methods: The study was based on the Stockholm-Gotland Obstetric Database (Sweden) from Jan $1^{\text {st }} 2008$ to Oct $22^{\text {nd }} 2014$ and included 113279 singleton spontaneous vaginal births with no episiotomy. We studied risk of OASIS with respect to the following birth positions: a) sitting, b) lithotomy, c) lateral, d) standing on knees, e) birth seat, f) supine, g) squatting, h) standing and i) all fours. All analyses were stratified for parity. General linear models were used to calculate risk ratios (RR) adjusted for maternal, pregnancy and fetal characteristics.

Results: The rates of OASIS among nulliparous women, parous women and women undergoing vaginal birth after a caesarean (VBAC) were $5.7 \%, 1.3 \%$ and $10.6 \%$, respectively. The rates varied by birth position: from 3.7 to $7.1 \%$ in nulliparous women, $0.6 \%$ to $2.6 \%$ in parous women and $5.6 \%$ to $18.2 \%$ in women undergoing VBAC. Regardless of parity, the lowest rates were found among women giving birth in standing position and the highest rates among women birthing in the lithotomy position. Compared with sitting position, the lithotomy position involved an increased risk of OASIS among nulliparous (adjusted RR 1.17, $95 \% \mathrm{Cl}$ 1.06-1.29) and parous women (adjusted RR 1.66, $95 \% \mathrm{Cl}$ 1.35-2.05). Birth seat and squatting position involved an increased risk of OASIS among parous women (adjusted RR [95 \% Cl] 1.36 [1.03-1.80] and 2.16 [1.15-4.07], respectively). Independent risk factors for OASIS were maternal age, head circumference $\geq 35 \mathrm{~cm}$, birth weight $\geq 4000 \mathrm{~g}$, length of gestation $\geq 40$ weeks, prolonged second stage of labour, non-occiput anterior presentation and oxytocin augmentation.

Conclusions: Compared with sitting position, lateral position has a slightly protective effect in nulliparous women whilst an increased risk is noted among women in the lithotomy position, irrespective of parity. Squatting and birth seat position involve an increase in risk among parous women.
\end{abstract}

Keywords: OASIS, Anal sphincter tear, Upright delivery, Perineal tear

\section{Background}

For centuries, pros and cons about different birth positions have been debated. For upright labour, several physiological advantages have been hypothesized and measured, such as effects of gravity, stronger uterine contractions, maternal satisfaction and feeling of control [1-3]. However, today the majority of women in the Western societies deliver in a dorsal, semi-

\footnotetext{
* Correspondence: li.thies-lagergren@med.lu.se

${ }^{2}$ The Department of Health Sciences, Faculty of Medicine, Lund University, Box 117, 22100 Lund, Sweden

Full list of author information is available at the end of the article
}

recumbent/sitting or lithotomy position [4-7]. It is claimed that these positions enable the attending midwife or obstetrician to monitor the fetus and facilitate a hands-on approach to perineal management to lower the risk of obstetric anal sphincter injuries (OASIS) [8].

Obstetric anal sphincter injuries are related to long term maternal complications, such as anal incontinence [9-11], sexual dysfunction [12], pain [13] and a reduced quality of life [14-16]. The rates of OASIS have increased in Sweden and in many other high-income countries over the last decades [17-20]. It has been unclear whether such trends reflect differences in 
populations, differences in diagnosis and registration, or differences in management of delivery between and within countries [19, 21-23].

Previously reported non-modifiable risk factors for OASIS are primiparity $[22,24]$, previous caesarean delivery [22, 25], high birth weight [17, 22, 24, 26-29], occiput posterior position [26, 17-30, 31], prolonged second stage of labour $[28,29,30]$ and increasing gestational age $[24,30]$. Studies disagree on whether maternal age influences risk of OASIS [5, 22, 17]. Modifiable risk factors include instrumental delivery $[20,25,28,17-31$, 32] augmentation [26] and midline episiotomy [32]. Inconsistent findings have also been reported for the association between birth position and OASIS $[4,5,33$, 34] Further, considering women's right to make choices concerning birth position, it is also important to examine associations between birth position and risk of OASIS.

The aim of this study was to investigate the association between birth position and occurrence of OASIS in spontaneous vaginal deliveries using a large populationbased cohort in Sweden.

\section{Methods}

Data on mother, delivery and infant characteristics were obtained from the population-based StockholmGotland Obstetric Database, based on the medical record system used for all maternity, delivery and postnatal care units in the region. Data from the medical record system is forwarded daily to the database, which contains information from 2008 and onwards. The database includes prospectively recorded standardized information from antenatal care, delivery (with partograph data) and the postpartum period for both mother and infant.

In Sweden, midwives are the primary caregivers during normal labour and birth. However, if complications occur, the midwife will notify an obstetrician. Swedish midwives diagnose and suture first and second degree perineal lacerations. If a midwife is unsure of the degree of the laceration or suspects a larger laceration (third or fourth degree), an obstetrician will be called upon for diagnosis and repair of the trauma.

\section{Study population}

During the study period (from January $1^{\text {st }}, 2008$, through Oct $\left.22^{\text {nd }}, 2014\right), 175522$ singleton births were recorded. We excluded cesarean and vaginal instrumental births $(n=49422)$, preterm births ( $\leq 36$ completed weeks; $n=4$ 408), births that required an episiotomy $(n=4508)$, births in non-cephalic presentations $(n=3749)$, and stillbirths $(n=156)$. The final study cohort consisted of 113279 live singleton term non-instrumental births.

\section{Exposures}

The midwife reported birth position in the medical record system within the next hours after birth. The recording system allowed the midwife to choose between seven different positions which (translated from Swedish) were; sitting, lithotomy, lateral, standing on knees, supine squatting, and standing. If another birth position was used it was documented using free text under the heading of "Other....". All births on the birth seat and in all fours position were collected from this heading. Remaining births in free text were sorted into appropriate birth positions if possible. The residual 166 births that were not understandable were collapsed with 583 births that did not have any information on birth position into the birth position category "unknown". There were no specific criteria for each position; the midwife freely decided which heading she/he judged to best describe the birth position used by the woman. The collected data does not reveal level of elevation of the head of the bed. In the present investigation, we used the following categories of birth position: a) sitting, b) lithotomy, c) lateral, d) standing on knees, e) birth seat, f) supine, g) squatting, h) standing or i) all fours. The most frequently used birth position was sitting, which was used as reference category.

\section{Outcome measurements}

The primary outcome was obstetric anal sphincter injury (OASIS). Cases were defined by having both a Diagnosis Related Groups (DRG) code (i.e. a surgical code for suturing of OASIS) in combination with a definition by the midwife or the obstetrician by a checkbox in the obstetric electronic case notes and/or International Classification of Diseases, tenth revision (ICD-10) code for sphincter injury. The DRG code used was MBC33 and the following ICD-10 codes: O702, O702C, O702D, O702X (grade III which involve the anal sphincter complex) and O703 (grade $\mathrm{IV}$, which extend to the rectal mucosa).

\section{Covariates}

Selection of potential confounding factors were based on biological plausibility and on results from previous studies. From the partograph and birth records we obtained information on maternal age, induction of labor, use of epidural analgesia (EDA), oxytocin augmentation, duration of second stage, head circumference, presentation, birth weight, and hospital delivery unit. Data on maternal weight and height for calculation of body mass index (BMI) was retrieved from 
the records of the first antenatal visit, usually in the first trimester. Hospital delivery unit was included as a potential confounder to adjust for potential cluster effects. Gestational age was determined using the following hierarchy: a) date of embryo transfer (3.0\%), b) early second trimester ultrasound (95.2\%), c) date of last menstrual period reported at the first antenatal visit $(1.8 \%)$ and d) from a postnatal assessment $(<1 \%)$. Duration of second stage was determined using the recordings of exact times in the mother's electronic case notes from full dilatation to delivery. This variable had $7 \%$ missing among nulliparous women and $24 \%$ missing among parous women.

\section{Statistical analyses}

Nulliparous and parous women were analysed separately. Furthermore, women with vaginal birth after a primary caesarean section (VBAC) have shown to be at higher risk for OASIS than both nulliparous and other parous women [34]. Women with VBAC $(n=2$ 828) were therefore included in a separate group. Characteristics of the nulliparous women, parous women and women undergoing VBAC in relation to birth position were estimated and presented along with prevalence rates of OASIS in descriptive Tables 1 and 2. Due to low numbers of OASIS in each birth position group, further analyses were not performed on the VBAC group.

We used general linear models to calculate risk ratios (RRs) and $95 \%$ confidence intervals (CI) to estimate associations between OASIS and the following categorical variables: maternal age ( $<35$ or $\geq 35$ years), maternal height $(<167$ or $\geq 167 \mathrm{~cm})$, BMI $\left(<25\right.$ or $\left.\geq 25 \mathrm{~kg} / \mathrm{m}^{2}\right)$, head circumference $(<35$ or $\geq 35 \mathrm{~cm})$, birth weight $(<4000$ or $\geq 4000 \mathrm{~g})$, gestational age $(<40$ or $\geq 40$ weeks), EDA (no/yes), augmentation with (synthetic) oxytocin (no/yes), duration of second stage $(<90$ or $\geq 90 \mathrm{~min}$ ), non-occiput anterior presentation (no/yes), induction (no/yes) hospital delivery units (A, B, C, D, E, F and G) and changes over time in years. In Sweden, dystocia during second stage refers to $>2 \mathrm{~h}$ for the descending phase alternatively $>3 \mathrm{~h}$ if epidural anesthesia is used, and $>1 \mathrm{~h}$ for the pushing phase. There are no clear differences made with regards to parity. Due to this quite unclear description and definition of a long second stage in Sweden we decided to use $90 \mathrm{~min}$ for all women.

The covariates were then entered into the multivariable model, and variables that remained significant after adjustments for either nulliparous or parous women were presented.

The statistical software package SPSS 20.0 (SPSS Inc., Chicago, IL, USA) was used for all data analyses. The regional ethical committee at Karolinska Institutet, Stockholm, Sweden approved the study protocol (No.
2009/275-31 and No. 2012/365-32). According to the Personal Data Act in Sweden, informed consent does not have to be obtained from each individual in this type of registry based research.

\section{Results}

In total, we studied 44942 births to nulliparous women, 65486 births to parous women, and 2828 births to women undergoing VBAC. The most frequently used birthing position was sitting, both among nulliparous women (38.5\%), parous women $(41.3 \%)$ and women undergoing VBAC (37.3 \%) (Fig. 1).

There were large variations in practice of birth positions amongst the seven in-hospital delivery units. For instance, the rate of the sitting position varied from 17.0 to $60.7 \%$ and the use of birth seat from 0.3 to $33.0 \%$ (Fig. 2).

Table 1 shows maternal, neonatal and obstetrical characteristics of the nulliparous women, parous women and women undergoing VBAC in relation to birth position. Irrespective of parity, women giving birth in the lithotomy position were characterized by high rates of induction, EDA, oxytocin augmentation, long second stages, infants with large head circumferences, high birth weights and births of infants presenting in non-occiput anterior presentations.

The prevalence of OASIS among nulliparous women was $5.7 \%$, among parous women $1.3 \%$ and among women undergoing VBAC $10.6 \%$ (Table 2). The rate of OASIS varied by birth position: from 3.7 to $7.1 \%$ in nulliparous women, $0.6 \%$ to $2.6 \%$ in parous women and $5.6 \%$ to $18.2 \%$ in women undergoing VBAC. The lowest rates were, regardless of parity, found among women giving birth in standing position.

Among nulliparous women and compared with the sitting position, the lithotomy position was associated with a modestly increased risk of OASIS in the adjusted analysis (Table 3). Only lateral position was associated with a reduced risk of OASIS in nulliparous women (adjusted RR 0.79, 95 \% CI 0.68-0.92).

Among parous women, the unadjusted analyses showed that lithotomy position was, compared with sitting position, associated with a more than two-fold increased risk of OASIS (Table 3). This increased risk was attenuated after adjustments. The birth seat position was associated with almost a $40 \%$ increased risk of OASIS, and this increased risk was not attenuated after adjustments. Also in parous women, squatting position was not significantly associated with OASIS in the univariate analyses. In in the adjusted analysis, squatting position was associated with a more than two-fold increased risk of OASIS (Table 3). Other birth positions were not associated with risk of OASIS in parous women. 
Table 1 Prevalence of maternal and neonatal characterstics in relation to birth position

\begin{tabular}{|c|c|c|c|c|c|c|c|c|c|c|c|c|}
\hline Characteristics (\%) & & Total & Sitting & Lithotomy & Lateral & Knee & Birth seat & Supine & Squatting & Standing & All fours & Unknown \\
\hline \multirow[t]{11}{*}{ Nulliparous women } & Number & 44942 & 17294 & 11906 & 5850 & 2660 & 4913 & 1214 & 342 & 243 & 235 & 285 \\
\hline & $\%$ & & & & & & & & & & & \\
\hline & Maternal age $>35$ years & 13 & 11 & 14 & 12 & 14 & 14 & 10 & 10 & 17 & 15 & 17 \\
\hline & Head circumference $>35 \mathrm{~cm}$ & 55 & 53 & 58 & 54 & 53 & 57 & 51 & 47 & 53 & 61 & 53 \\
\hline & Birthweight > $4000 \mathrm{~g}$ & 11 & 10 & 14 & 10 & 10 & 11 & 10 & 10 & 12 & 14 & 12 \\
\hline & Length of second stage $>90 \mathrm{~min}$ & 45 & 43 & 58 & 27 & 35 & 39 & 36 & 39 & 37 & 40 & 45 \\
\hline & Gestational age $>40$ weeks & 60 & 59 & 63 & 59 & 59 & 62 & 54 & 57 & 61 & 65 & 59 \\
\hline & Induction & 15 & 14 & 19 & 14 & 10 & 11 & 14 & 13 & 7 & 8 & 18 \\
\hline & Epidural analgesia & 57 & 57 & 68 & 53 & 43 & 51 & 50 & 56 & 42 & 53 & 55 \\
\hline & Non-occiput anterior presentation & 3 & 2 & 4 & 2 & 1 & 2 & 2 & 3 & 3 & 2 & 14 \\
\hline & Oxytocin augmentation & 61 & 60 & 79 & 52 & 43 & 50 & 50 & 54 & 40 & 51 & 58 \\
\hline \multirow[t]{11}{*}{ Parous women } & Number & 65486 & 27054 & 7410 & 12631 & 7478 & 5025 & 3687 & 469 & 858 & 427 & 447 \\
\hline & $\%$ & & & & & & & & & & & \\
\hline & Maternal age $>35$ years & 35 & 32 & 36 & 36 & 41 & 40 & 31 & 34 & 45 & 41 & 35 \\
\hline & Head circumference $>35 \mathrm{~cm}$ & 65 & 62 & 71 & 67 & 67 & 71 & 59 & 63 & 67 & 69 & 65 \\
\hline & Birthweight $>4000 \mathrm{~g}$ & 22 & 20 & 29 & 22 & 23 & 24 & 16 & 22 & 24 & 28 & 24 \\
\hline & Length of second stage $>90 \mathrm{~min}$ & 7 & 5 & 16 & 5 & 4 & 7 & 3 & 9 & 7 & 8 & 6 \\
\hline & Gestational age $>40$ weeks & 57 & 55 & 61 & 57 & 59 & 61 & 52 & 57 & 59 & 61 & 56 \\
\hline & Induction & 14 & 14 & 21 & 14 & 9 & 9 & 15 & 11 & 10 & 11 & 33 \\
\hline & Epidural analgesia & 26 & 26 & 39 & 25 & 19 & 28 & 18 & 28 & 16 & 20 & 24 \\
\hline & Non-occiput anterior presentation & 4 & 3 & 7 & 4 & 2 & 4 & 3 & 4 & 2 & 3 & 20 \\
\hline & Oxytocin augmentation & 26 & 25 & 48 & 23 & 17 & 23 & 20 & 25 & 16 & 19 & 22 \\
\hline \multirow[t]{11}{*}{ Women undergoing VBAC } & Number & 2828 & 1054 & 864 & 387 & 149 & 225 & 77 & 21 & 18 & 16 & 17 \\
\hline & $\%$ & & & & & & & & & & & \\
\hline & Maternal age $>35$ years & 31 & 28 & 32 & 32 & 37 & 29 & 29 & 38 & 50 & 38 & 35 \\
\hline & Head circumference $>35 \mathrm{~cm}$ & 63 & 62 & 67 & 62 & 68 & 61 & 54 & 57 & 71 & 75 & 53 \\
\hline & Birthweight $>4000 \mathrm{~g}$ & 18 & 19 & 18 & 18 & 18 & 17 & 12 & 19 & 22 & 50 & 0 \\
\hline & Length of second stage $>90 \mathrm{~min}$ & 39 & 36 & 50 & 34 & 23 & 42 & 29 & 40 & 12 & 31 & 29 \\
\hline & Gestational age $>40$ weeks & 61 & 60 & 62 & 62 & 55 & 68 & 58 & 62 & 56 & 69 & 47 \\
\hline & Induction & 15 & 14 & 18 & 13 & 11 & 11 & 10 & 24 & 6 & 6 & 18 \\
\hline & Epidural analgesia & 62 & 60 & 71 & 58 & 53 & 59 & 56 & 67 & 33 & 69 & 47 \\
\hline & Non-occiput anterior presentation & 2 & 2 & 3 & 2 & 0 & 2 & 1 & 5 & 6 & 6 & 18 \\
\hline & Oxytocin augmentation & 58 & 55 & 71 & 49 & 41 & 51 & 48 & 57 & 28 & 63 & 53 \\
\hline
\end{tabular}


Table 2 Prevalence (\%) of OASIS in relation to birth position

\begin{tabular}{|c|c|c|c|c|c|c|c|c|c|c|c|c|}
\hline & & Total & Sitting & Lithotomy & Lateral & Knee & Birth seat & Supine & Squatting & Standing & All fours & Unknown \\
\hline \multirow[t]{4}{*}{ Nulliparous women } & $\mathrm{N}$ of OASIS & 2548 & 931 & 850 & 250 & 126 & 279 & 58 & 15 & 9 & 13 & 17 \\
\hline & OASIS (\%) & 5.7 & 5.4 & 7.1 & 4.3 & 4.7 & 5.7 & 4.8 & 4.4 & 3.7 & 5.5 & 6.0 \\
\hline & 3rd degree (\%) & 5.2 & 4.9 & 6.5 & 4.0 & 4.3 & 5.1 & 4.4 & 3.8 & 3.7 & 5.5 & 5.5 \\
\hline & 4th degree (\%) & 0.5 & 0.5 & 0.6 & 0.3 & 0.4 & 0.6 & 0.4 & 0.6 & 0.0 & 0.0 & 0.5 \\
\hline \multirow[t]{4}{*}{ Parous women } & $\mathrm{N}$ of OASIS & 859 & 323 & 194 & 124 & 70 & 82 & 37 & 10 & 5 & 6 & 8 \\
\hline & OASIS (\%) & 1.3 & 1.2 & 2.6 & 1.0 & 0.9 & 1.6 & 1.0 & 2.1 & 0.6 & 1.4 & 1.8 \\
\hline & 3rd degree (\%) & 1.1 & 1.1 & 2.0 & 0.9 & 0.8 & 1.4 & 0.9 & 1.7 & 0.6 & 1.2 & 1.7 \\
\hline & 4th degree (\%) & 0.2 & 0.1 & 0.6 & 0.1 & 0.1 & 0.2 & 0.1 & 0.4 & 0.0 & 0.2 & 0.1 \\
\hline \multirow{4}{*}{$\begin{array}{l}\text { Women undergoing } \\
\text { VBAC }\end{array}$} & $\mathrm{N}$ of OASIS & 301 & 100 & 106 & 32 & 16 & 27 & 13 & 3 & 1 & 1 & 2 \\
\hline & OASIS (\%) & 10.6 & 9.5 & 12.3 & 8.3 & 10.7 & 12.0 & 18.2 & 14.3 & 5.6 & 6.3 & 11.8 \\
\hline & 3rd degree (\%) & 10.2 & 9.5 & 10.9 & 7.4 & 10.7 & 11.6 & 18.2 & 14.3 & 5.6 & 1.2 & 11.8 \\
\hline & 4th degree (\%) & 0.6 & 0.0 & 1.4 & 1.0 & 0.0 & 0.4 & 0.0 & 0.0 & 0.0 & 0.2 & 0.0 \\
\hline
\end{tabular}

In multivariate analyses of nulliparous and parous women, we also found the following factors to be associated with increased risk of OASIS: large head circumference, high birth weight, prolonged second stage of labour, gestational age $\geq 40$ weeks, and non-occiput anterior presentation (Table 3). High maternal age, oxytocin augmentation and hospital delivery unit was only associated with increased risk of OASIS in nulliparous women. Epidural analgesia had a protective effect in nulliparous women but was not significantly associated with OASIS in parous women. Maternal height, BMI and induction were not associated with increased risks of OASIS in the adjusted analysis (data not shown).

\section{Discussion}

We found that the lithotomy position was associated with increased risk of OASIS, especially in parous women. The less frequently used birth seat and squatting position also implied an increased risk of OASIS in parous women. Compared with the reference category of sitting position, lateral position was associated with a slightly protective effect in nulliparous women.

Irrespective of parity, births in the lithotomy position had higher rates of OASIS but were more often accompanied by other risk factors for OASIS, such as high birth weight, large head circumference, non-occiput anterior presentation, oxytocin augmentation and a prolonged second stage of labour. These factors partly explained the association between lithotomy position and risk of OASIS. The increased risk that remained after adjustments supports findings from a Swedish observational cohort study [4]. Two additional studies have shown slightly increased risks of perineal trauma in lithotomy position, but these studies were not powered to specifically study birth position and risk of OASIS [35, 36]. Possible explanations of the association between lithotomy

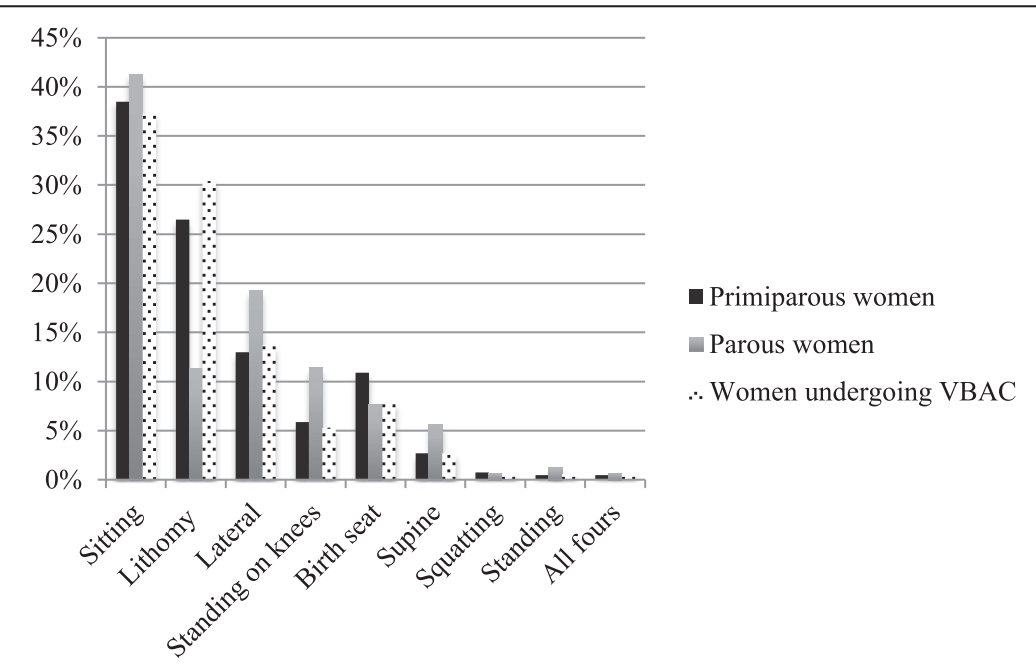

Fig. 1 Rates of birthing positions (\%) among nulliparous women, parous women and women undergoing VBAC, respectively 


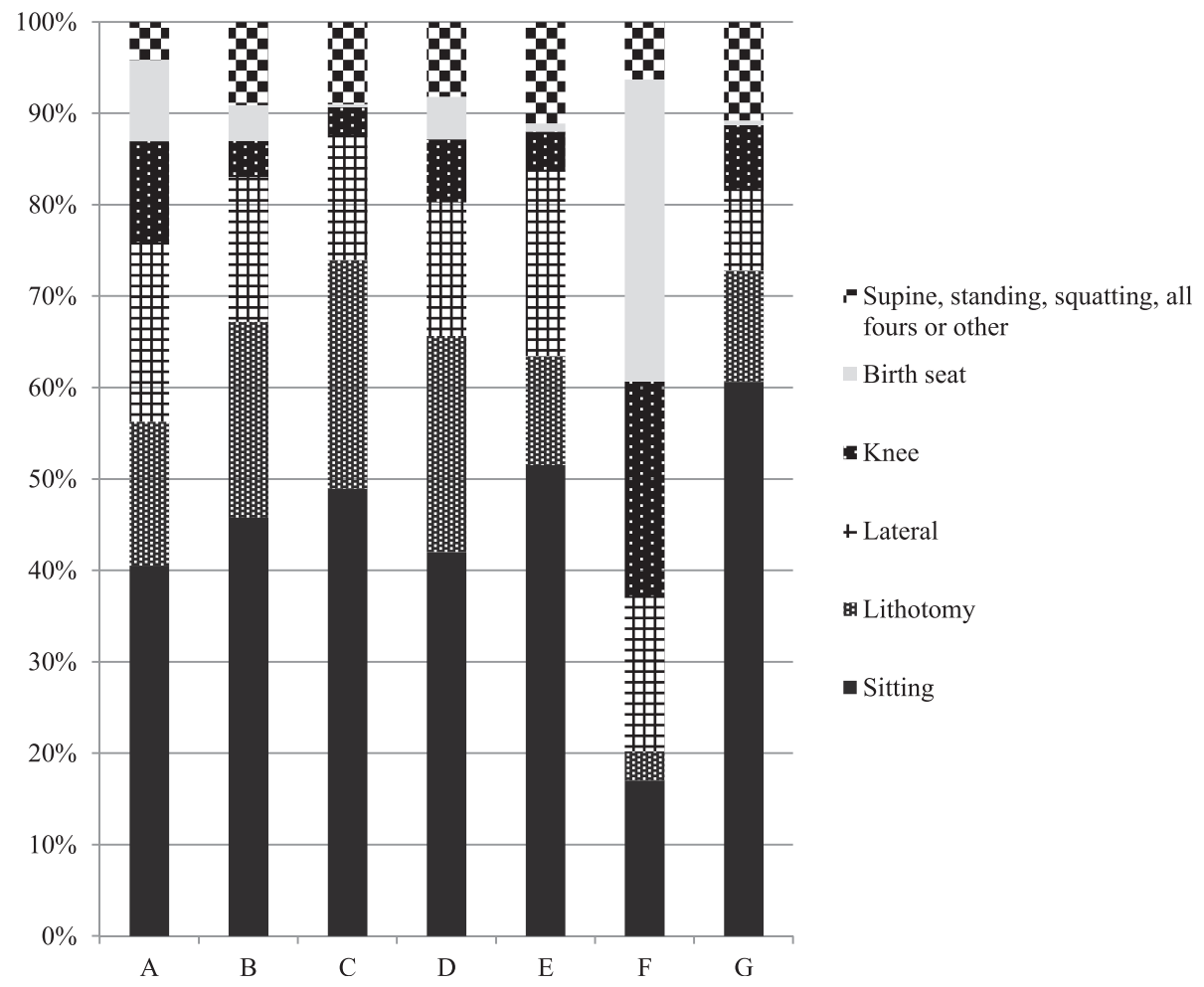

Fig. 2 Rates (\%) of birth positions used in relation to in-hospital birth unit (a-g)

birth position and risk of OASIS may be that lithotomy position increases pressure sensations in the perineal area and decreases the woman's ability to moderate the tempo of her own pushing efforts [35]. Further, the lithotomy position might increases the risk of OASIS by causing a greater pressure towards the sphincter during the expulsion of the infant compared with alternate positions.

We found a doubled risk of OASIS in squatting position among parous women. The increased risk in this position has been reported previously [4]. In contrast to others [5], we analysed birth seat position and squatting separately. Women in the squatting position lean forward more than women in the birth seat position who most often lean back into the arms of their partner sitting behind on a chair. Although an association between birth seat position and increase in second-degree tears previously has been reported [8], the association between birth seat and increased risk of OASIS in parous women found in our study is a novel and important finding. It is plausible that both the squatting position and the use of birth seat may lead to a too rapid expulsatory phase in parous women. This, in combination with challenging circumstances for the midwife to hands on protect the perineum may increase the risk of OASIS. Slowing the delivery of the infants' head and supporting the perineum are interventions that have shown to lower the risk of OASIS [37].
The increased rate of OASIS among women undergoing VBAC may be explained by fetopelvic disproportion leading to a primary caesarean section possibly predisposing to OASIS at first vaginal delivery $[25,38]$. We lacked information about indication for these women's caesarean sections and if the birthing process in women undergoing VBAC differed from non-VBAC women.

The $6 \%$ rate of OASIS among nulliparous women in our study population is reflected by the official rate reported by The National Board of Health and Welfare [39]. There is a significant difference in the Nordic countries in the incidence of OASIS [23]. It has been hypothesized that differences in delivery techniques and use of episiotomies may be one reason [23]. Although a Norweigan intervention study suggest that the obstetric practice and hands on practice makes a difference [37] another meta-analysis concluded that hands off (or poised) versus hands on showed no effect on third- and fourth-degree tears [40]. In Sweden, episiotomies are uncommon with a rate of $<8 \%$ among nulliparous women, while in Norway and Finland, corresponding rates are $23 \%$ and $65 \%$, respectively [37, 41].

\section{Strengths and limitations}

Major strengths of this study are the large sample size of births from all maternity and delivery units within a geographically defined area, and that data were obtained 
Table 3 Unadjusted and adjusted risk ratios and $95 \%$ CI for OASIS among nulliparous and parous

\begin{tabular}{|c|c|c|c|c|}
\hline & \multicolumn{2}{|c|}{ Nulliparous ( $n=44942)$} & \multicolumn{2}{|l|}{ Parous $(n=65486)$} \\
\hline & Unadjusted risk ratio & Adjusted risk ratio* & Unadjusted risk ratio & Adjusted risk ratio* \\
\hline & $95 \% \mathrm{Cl}$ & $95 \% \mathrm{Cl}$ & $95 \% \mathrm{Cl}$ & $95 \% \mathrm{Cl}$ \\
\hline \multicolumn{5}{|l|}{ Total } \\
\hline Sitting & 1.00 & 1.00 & 1.00 & 1.00 \\
\hline Lithotomy & $1.33(1.21-1.46)$ & $1.17(1.06-1.29)$ & $2.19(1.83-2.62)$ & $1.66(1.35-2.05)$ \\
\hline Lateral & $0.79(0.69-0.91)$ & $0.79(0.68-0.92)$ & $0.82(0.67-1.01)$ & $0.84(0.66-1.06)$ \\
\hline Knee & $0.88(0.73-1.06)$ & $0.88(0.71-1.09)$ & $0.78(0.60-1.00)$ & $0.81(0.58-1.11)$ \\
\hline Birth seat & $1.05(0.92-1.21)$ & $1.05(0.90-1.22)$ & $1.37(1.07-1.74)$ & $1.36(1.03-1.80)$ \\
\hline Supine & $0.89(0.68-1.16)$ & $0.91(0.67-1.22)$ & $0.84(0.60-1.18)$ & $0.84(0.55-1.30)$ \\
\hline Squatting & $0.81(0.49-1.36)$ & $0.66(0.36-1.24)$ & $1.79(0.95-3.35)$ & $2.16(1.15-4.07)$ \\
\hline Standing & $0.69(0.36-1.33)$ & $0.71(0.34-1.49)$ & $0.49(0.20-1.18)$ & $0.40(0.10-1.61)$ \\
\hline All four & $1.03(0.59-1.78)$ & $1.12(0.62-2.05)$ & $1.18(0.53-2.64)$ & $0.95(0.30-2.96)$ \\
\hline \multicolumn{5}{|c|}{ Maternal age (years) } \\
\hline$<35$ & 1.00 & 1.00 & 1.00 & 1.00 \\
\hline$>35$ & $1.25(1.12-1.39)$ & $1.21(1.08-1.36)$ & $1.13(0.99-1.30)$ & $1.12(0.96-1.32)$ \\
\hline \multicolumn{5}{|c|}{ Head circumference } \\
\hline$<35$ & 1.00 & 1.00 & 1.00 & 1.00 \\
\hline$>35$ & $1.76(1.62-1.92)$ & $1.42(1.29-1.57)$ & $1.95(1.65-2.31)$ & $1.52(1.23-1.88)$ \\
\hline \multicolumn{5}{|l|}{ Birth weight } \\
\hline$<4000 \mathrm{~g}$ & 1.00 & 1.00 & 1.00 & 1.00 \\
\hline$>4000 \mathrm{~g}$ & $2.16(1.96-2.39)$ & $1.69(1.52-1.88)$ & $2.54(2.22-2.91)$ & $1.86(1.57-2.21)$ \\
\hline \multicolumn{5}{|c|}{ Length of second stage } \\
\hline$<90 \min$ & 1.00 & 1.00 & 1.00 & 1.00 \\
\hline$>90 \min$ & $1.36(1.25-1.47)$ & $1.15(1.05-1.26)$ & $2.44(1.98-3.01)$ & $1.93(1.53-2.45)$ \\
\hline \multicolumn{5}{|c|}{ Length of gestation (weeks) } \\
\hline$<40$ & 1.00 & 1.00 & 1.00 & 1.00 \\
\hline$>40$ & $1.50(1.38-1.64)$ & $1.20(1.09-1.31)$ & $1.64(1.42-1.87)$ & $1.25(1.04-1.49)$ \\
\hline \multicolumn{5}{|c|}{ Epidural analgesia } \\
\hline No & 1.00 & 1.00 & 1.00 & 1.00 \\
\hline Yes & $1.02(0.94-1.10)$ & $0.82(0.74-0.90)$ & $1.28(1.11-1.47)$ & $1.01(0.88-1.24)$ \\
\hline \multicolumn{5}{|c|}{ Non-occiput anterior presentation } \\
\hline No & 1.00 & 1.00 & 1.00 & 1.00 \\
\hline Yes & $1.48(1.20-1.82)$ & $1.30(1.01-1.68)$ & $1.92(1.47-2.51)$ & $1.51(1.10-2.05)$ \\
\hline \multicolumn{5}{|c|}{ Oxytocin augmentation } \\
\hline No & 1.00 & 1.00 & 1.00 & 1.00 \\
\hline Yes & $1.31(1.21-1.42)$ & $1.21(1.09-1.35)$ & $1.33(1.15-1.53)$ & $0.93(0.78-1.12)$ \\
\hline
\end{tabular}

*Adjusted for all other variables in table + time in years + in-hospital delivery unit

from prospectively recorded information in antenatal and obstetrical records. We were able to control for a number of possible confounders, including cluster variation between hospitals. The restriction of analyses to women with no episiotomy is a strength as it increases clarity although it limits generalizability. Lack of information on fundal pressure [26] and perineal protection is a limitation. Midwives may use various perineal management techniques [40] and such information was not systematically documented. Furthermore, we were unable to analyse the midwives' experience and training, which could impact on outcome. However, all midwives at the hospital delivery units have received similar midwifery training even though the attitudes towards encouraging women to deliver in alternate positions might differ $[8,42]$. 
This is an observational study, and the results cannot be causally interpreted. However, the findings are biologically plausible and have partially been supported in other studies $[4,8,43]$.

\section{Conclusion}

Compared with sitting position, lateral position has a slightly protective effect in nulliparous whilst an increased risk is noted among women in the lithotomy position, irrespective of parity. Births in the lithotomy position were accompanied by other risk factors for OASIS which partly explained the elevated risk. Squatting and birth seat position involved an increase in risk among parous women.

\section{Competing interest}

The authors declare that they have no competing interests.

\section{Authors' contributions}

CE developed the original idea for the study, performed the analyses and wrote a majority of the manuscript. SC, OS, MA and LTL assisted with design and interpretation of study findings and contributed to writing and revising the manuscript. All authors read and approved the final manuscript.

\section{Acknowledgements}

This study was supported by grants from the Swedish Research Council (2013-2429, OS and 2008-5857, SC) by grants provided by the Stockholm County Council (ALF projects 20130156, OS and 20140105, SC) and by the Swedish National Doctoral School in Health Care Sciences (CE).

\section{Author details}

${ }^{1}$ Department of Medicine, Division of Clinical Epidemiology, T2, Karolinska University Hospital, 17176 Stockholm, Sweden. ${ }^{2}$ The Department of Health Sciences, Faculty of Medicine, Lund University, Box 117, 22100 Lund, Sweden.

Received: 1 June 2015 Accepted: 5 October 2015

Published online: 09 October 2015

\section{References}

1. Michel SC, Rake A, Treiber K, Seifert B, Chaoui R, Huch R, et al. MR obstetric pelvimetry: effect of birthing position on pelvic bony dimensions. AJR Am J Roentgenol. 2002;179(4):1063-7.

2. Berghella V, Baxter JK, Chauhan SP. Evidence-based labor and delivery management. Am J Obstet Gynecol. 2008;199(5):445-54.

3. Simpson KR. When and how to push: providing the most current information about second-stage labor to women during childbirth education. J Perinat Educ. 2006;15(4):6-9.

4. Gottvall K, Allebeck P, Ekeus C. Risk factors for anal sphincter tears: the importance of maternal position at birth. BJOG. 2007;114(10):1266-72.

5. Haslinger C, Burkhardt T, Stoiber B, Zimmermann R, Schaffer L. Position at birth as an important factor for the occurrence of anal sphincter tears: a retrospective cohort study. Journal of perinatal medicine. 2014. doi:10.1515/ jpm-2014-0172.

6. Sakala C, Declercq ER, Corry MP. Listening to Mothers: the first national U.S survey of women's childbearing experiences. J Obstet Gynecol Neonatal Nurs. 2002;31(6):633-4.

7. Sandin-Bojo AK, Kvist LJ. Care in labor: a Swedish survey using the Bologna Score. Birth. 2008;35(4):321-8

8. Gupta JK, Hofmeyr GJ, Shehmar M. Position in the second stage of labour for women without epidural anaesthesia. Cochrane Database Syst Rev. 2012;5:CD002006.

9. Borello-France D, Burgio KL, Richter HE, Zyczynski H, Fitzgerald MP, Whitehead W, et al. Fecal and urinary incontinence in primiparous women. Obstet Gynecol. 2006;108(4):863-72.
10. Pollack J, Nordenstam J, Brismar S, Lopez A, Altman D, Zetterstrom J. Anal incontinence after vaginal delivery: a five-year prospective cohort study. Obstet Gynecol. 2004;104(6):1397-402.

11. Fenner DE, Genberg B, Brahma P, Marek L, DeLancey JO. Fecal and urinary incontinence after vaginal delivery with anal sphincter disruption in an obstetrics unit in the United States. Am J Obstet Gynecol. 2003;189(6):1543-9. discussion 9-50.

12. Andrews $V$, Thakar $R$, Sultan $A H$, Jones PW. Evaluation of postpartum perineal pain and dyspareunia-a prospective study. Eur J Obstet Gynecol Reprod Biol. 2008;137(2):152-6.

13. Macarthur AJ, Macarthur C. Incidence, severity, and determinants of perineal pain after vaginal delivery: a prospective cohort study. Am J Obstet Gynecol. 2004;191(4):1199-204.

14. Handa VL, Zyczynski HM, Burgio KL, Fitzgerald MP, Borello-France D, Janz NK, et al. The impact of fecal and urinary incontinence on quality of life 6 months after childbirth. Am J Obstet Gynecol. 2007;197(6):636. e1-6.

15. Bharucha AE, Zinsmeister AR, Locke GR, Seide BM, McKeon K, Schleck CD, et al. Prevalence and burden of fecal incontinence: a population-based study in women. Gastroenterology. 2005;129(1):42-9.

16. Evers EC, Blomquist JL, McDermott KC, Handa VL. Obstetrical anal sphincter laceration and anal incontinence 5-10 years after childbirth. Am J Obstet Gynecol. 2012;207(5):425. e1-6.

17. Ekeus C, Nilsson E, Gottvall K. Increasing incidence of anal sphincter tears among primiparas in Sweden: a population-based register study. Acta Obstet Gynecol Scand. 2008;87(5):564-73.

18. Ampt AJ, Ford JB, Roberts CL, Morris JM. Trends in obstetric anal sphincter injuries and associated risk factors for vaginal singleton term births in New South Wales 2001-2009. Aust N Z J Obstet Gynaecol. 2013;53(1):9-16.

19. Laine K, Gissler M, Pirhonen J. Changing incidence of anal sphincter tears in four Nordic countries through the last decades.Eur J Obstet Gynecol Reprod Biol 2009;146(1): 71-75.

20. Ismail SI, Puyk B. The rise of obstetric anal sphincter injuries (OASIS): 11-year trend analysis using Patient Episode Database for Wales (PEDW) data. J Obstet Gynaecol. 2014;34(6):495-8.

21. Baghurst PA. The case for retaining severe perineal tears as an indicator of the quality of obstetric care. Aust N Z J Obstet Gynaecol. 2013;53(1):3-8.

22. Baghestan $E$, Irgens LM, Bordahl PE, Rasmussen $S$. Trends in risk factors for obstetric anal sphincter injuries in Norway. Obstet Gynecol. 2010;116(1):25-33.

23. Laine K, Gissler M, Pirhonen J. Changing incidence of anal sphincter tears in four Nordic countries through the last decades. Eur J Obstet Gynecol Reprod Biol. 2009;146(1):71-5.

24. Zetterstrom J, Lopez A, Anzen B, Norman M, Holmstrom B, Mellgren A. Anal sphincter tears at vaginal delivery: risk factors and clinical outcome of primary repair. Obstet Gynecol. 1999;94(1):21-8.

25. Raisanen S, Vehvilainen-Julkunen K, Cartwright R, Gissler M, Heinonen S. A prior cesarean section and incidence of obstetric anal sphincter injury. Int Urogynecol J. 2013;24(8):1331-9.

26. Jangö H, Langhoff-Roos J, Rosthøj S, Sakse A. Modifiable risk factors of obstetric anal sphincter injury in primiparous women:a population-based cohort study. Am J Obstet Gynecol. 2014;210(1):59. e51-56.

27. Christianson LM, Bovbjerg VE, McDavitt EC, Hullfish KL. Risk factors for perineal injury during delivery. Am J Obstet Gynecol. 2003;189(1):255-60.

28. Hudelist G, Gelle'n J, Singer C, Ruecklinger E, Czerwenka K, Kandolf O, et al. Factors predicting severe perineal trauma during childbirth: role of forceps delivery routinely combined with mediolateral episiotomy. Am J Obstet Gynecol. 2005;192(3):875-81.

29. Samuelsson E, Ladfors L, Wennerholm UB, Gareberg B, Nyberg K, Hagberg $\mathrm{H}$. Anal sphincter tears: prospective study of obstetric risk factors. BJOG. 2000;107(7):926-31.

30. Fitzgerald MP, Weber AM, Howden N, Cundiff GW, Brown MB. Risk factors for anal sphincter tear during vaginal delivery. Obstet Gynecol. 2007;109(1):29-34.

31. Wheeler 2nd TL, Richter HE. Delivery method, anal sphincter tears and fecal incontinence: new information on a persistent problem. Curr Opin Obstet Gynecol. 2007;19(5):474-9.

32. Signorello LB, Harlow BL, Chekos AK, Repke JT. Midline episiotomy and anal incontinence: retrospective cohort study. BMJ. 2000;320:86-90.

33. Altman D, Ragnar I, Ekstrom A, Tyden T, Olsson SE. Anal sphincter lacerations and upright delivery postures - a risk analysis from a 
randomized controlled trial. Int Urogynecol J Pelvic Floor Dysfunct. 2007;18(2):141-6.

34. Jander $C$, Lyrenas $S$. Third and fourth degree perineal tears. Predictor factors in a referral hospital. Acta Obstet Gynecol Scand. 2001;80(3):229-34.

35. Albers LL, Anderson D, Cragin L, Daniels SM, Hunter C, Sedler KD, et al. Factors related to perineal trauma in childbirth. J Nurse Midwifery. 1996;41(4):269-76.

36. Soong B, Barnes M. Maternal position at midwife-attended birth and perineal trauma: Is there an association? Birth-Iss Perinat C. 2005;32(3):164-9.

37. Laine K, Skjeldestad FE, Sandvik L, Staff AC. Incidence of obstetric anal sphincter injuries after training to protect the perineum: cohort study. BMJ open. 2012;2(5).

38. Richter HE, Brumfield CG, Cliver SP, Burgio KL, Neely CL, Varner RE. Risk factors associated with anal sphincter tear: a comparison of primiparous patients, vaginal births after cesarean deliveries, and patients with previous vaginal delivery. Am J Obstet Gynecol. 2002;187(5):1194-8.

39. Swedish National Board of Health and Welfare. Statistical database of pregnancies, births and newborns. http://www.socialstyrelsen.se/statistik/ statistikdatabas/graviditeter-forlossningarochnyfodda. Accessed 20 May 2015.

40. Aasheim V, Nilsen ABV, Lukasse M, Reinar LM. Perineal techniques during the second stage of labour for reducing perineal trauma. Cochrane Database Syst Rev. 2011;12:CD006672.

41. Raisanen SH, Vehvilainen-Julkunen K, Gissler M, Heinonen S. Lateral episiotomy protects primiparous but not multiparous women from obstetric anal sphincter rupture. Acta Obstet Gynecol Scand. 2009;88(12):1365-72.

42. Kemp E, Kingswood CJ, Kibuka M, Thornton JG. Position in the second stage of labour for women with epidural anaesthesia. Cochrane Database Syst Rev. 2013;1:CD008070.

43. Thies-Lagergren L, Kvist L, Christensson K, Hildingsson I. No reduction in instrumental vaginal births and no increased risk for adverse perineal outcome in nulliparous women giving birth on a birth seat: results of a Swedish randomized controlled trial. BMC Pregnancy Childbirth. 2011;11:22.

\section{Submit your next manuscript to BioMed Central and take full advantage of:}

- Convenient online submission

- Thorough peer review

- No space constraints or color figure charges

- Immediate publication on acceptance

- Inclusion in PubMed, CAS, Scopus and Google Scholar

- Research which is freely available for redistribution 